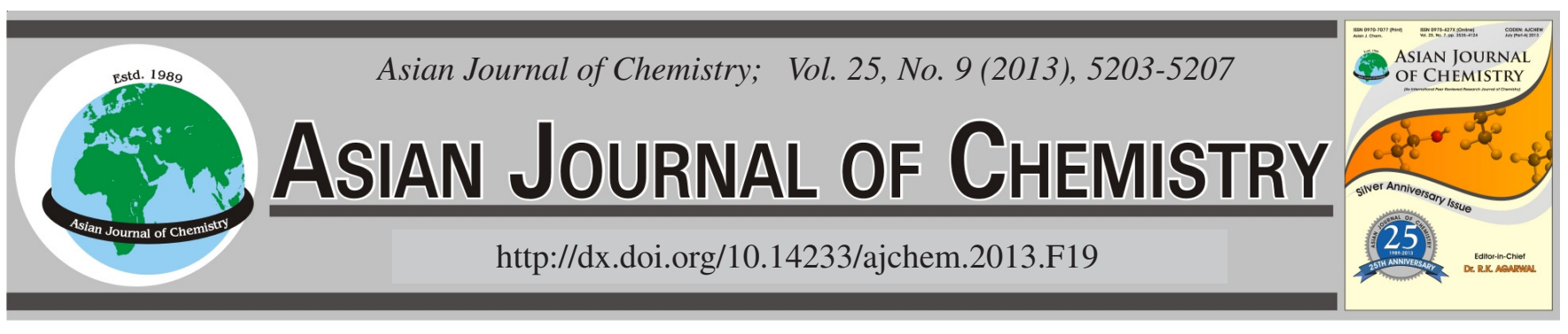

\title{
Effect of Rubber Mixing Sequence Variation Upon Bound Rubber Formation and Its Physical Properties $\dagger$
}

\author{
Abu Hasan ${ }^{1, *}$, Rochmadi $^{2}$, Hary Sulistyo $^{2}$ and Suharto Honggokusumo ${ }^{3}$
}

${ }^{1}$ Chemical Engineering Department, State Polytechnic of Sriwijaya, Jln. Srijaya Negara Bukit Besar Palembang 30139, Indonesia ${ }^{2}$ Chemical Engineering Department, Faculty of Engineering Gadjah Mada University Jln. Grafika no 2 Yogyakarta 55281, Indonesia ${ }^{3}$ Gapkindo (The Indonesian Rubber Association) Jln. Cideng Barat no 62A Jakarta 10150, Indonesia

*Corresponding author: Fax: +62 711 355918; Tel: +62 711 353414; E-mail: abu_hasan@polsri.ac.id

AJC-13174

This study examined the effect of mastication and the addition sequence of rubber chemicals and filler during the mixing process on the formation of bound rubber and the physical properties of the natural rubber vulcanizates. An analysis of the curing characteristics, rubber bound formation and physical properties of vulcanizates were carried out on a natural rubber formula that had been masticated and mixing, followed by curing. Two methods of mastication were used and each mastication process was followed by four different mixing sequences. In the first mastication method, rubber was masticated for $5 \mathrm{~min}$, which was followed by the simultaneous addition of rubber chemicals and carbon black N 330. In the second method, rubber was masticated for 3 min and carbon black and rubber chemicals were added subsequently. The addition of rubber chemicals and carbon black into the masticated rubber was distinguished by the sequence and time allocated for each mixing process. Carbon black was added into two stages. In the first stage, 10 phr was added first and the remaining $40 \mathrm{phr}$ was added later along with oil. In the other methods, carbon black was added in the first and second stage at the following ratios: 20:30, 30:20 and 40:10. The second method formed more strongly bound rubber with superior physical properties than that of the first method. The difference in those results was attributed to the mastication time. The softness of the masticated rubber produced increased with increasing mastication time. This means that softer masticated rubber possessed a low shearing force to break the carbon black aggregates and produced a poor dispersion in the rubber. Therefore, less bound rubber was formed. The second method, which was 40:10, gave the best results. More carbon black mixed in the first stage without the addition of processing oil and rubber chemicals gave rise to a better dispersion than when less carbon black was mixed.

Key Words: Carbon black, Natural rubber, Bound rubber, Physical properties.

\section{INTRODUCTION}

In the rubber goods industry, the filler is used not only to reduce the production cost without degrading the rubber goods quality, but also to improve the strength of the rubber products. The quality of the rubber goods can also be improved by adjusting the rubber vulcanization system and additives.

Vulcanization itself depends on the type of rubber. A sulfur vulcanization system is employed in rubber containing a double bond, e.g. natural rubber ${ }^{1}$. The sulfur vulcanization system forms a crosslink network among the rubber molecules, resulting in a three dimensional structure. As a result, the rubber changes its nature from a plastic like soft material to a strong elastic product. The physical properties, such as the tensile strength, modulus and elongation at break, are enhanced $^{2}$. An improvement in the quality of rubber goods by enhancing the physical properties can also be achieved by the addition of a filler. The addition of a filler in a certain manner can increase the amount of bound rubber. The extent of bound rubber formation is expected to increase with increasing amount of filler and decreasing size of the carbon black particles added ${ }^{3}$. The structure of carbon black also affects the bound rubber formation. An increase in the structure of carbon black is expected to increase the formation of bound rubber formation. The crosslink density would also increase with increasing carbon black content ${ }^{4}$. A certain mixing sequence of the rubber ingredients in the process of compounding might increase the abrasion resistance due to the increased crosslink density associated with the formation of bound rubber. In this study, the addition of carbon black during compounding was carried out in two methods. In the first method, oil was added after carbon black had been incorporated into the rubber and 
in the second method, oil was added to the rubber together with the carbon black. The first method gave higher abrasion resistance than the second one ${ }^{5}$. The addition sequence of compounding ingredients in the rubber mixing process was also studied to determine its effects on the dynamic characteristics of rubber vulcanizates ${ }^{6,7}$. The dynamic characteristics are classified as the viscous modulus, elastic modulus and loss factor. The sequence of a rubber mixing process can alter the carbon black surface; large aggregates become smaller, resulting in an increase in surface area. This characteristic of the surface area could intensify the interaction between carbon black and rubber ${ }^{8}$. Dannenberg classified the mixing variable as one of the factors affecting the formation of bound rubber? Although the sequence of the rubber mixing process has been studied, there are no reports specifying the method of carbon black addition to rubber and the length of the rubber mastication time before adding the filler and rubber chemicals. Therefore, this study examined the effects of the mastication time and the sequence of the addition of rubber chemicals and filler into rubber. The process of carbon black addition into rubber was carried out in various quantities and its effect on the formation of bound rubber and physical properties enhancement were studied.

\section{EXPERIMENTAL}

The main raw materials used in this experiment were natural rubber ribbed smoked sheet-1 (RSS-1) produced in Indonesia and carbon black filler N 330 type from Cobot Indonesia. The rubber chemicals consisted of sulfur, tert-butyl benzothiazole sulfenamide (TBBS), tetra methyl quinone (TMQ), zinc oxide $(\mathrm{ZnO})$, stearic acid and processing oil. Toluene was used to determine the bound rubber level. All materials and chemicals were of commercial grade and were used as received. The equipment used in this experiment consisted of an open two roll mill, rheometer MDR 2000, temperature thermocouple, extensometer, tear strength tester, abrasion resistance tester and glassware for the bound rubber test.

General procedure: Rubber was masticated for $5 \mathrm{~min}$. Rubber chemicals and the filler listed in Table- 1 were mixed in an open two-roll mill according to the mixing sequence listed in Table-2. The samples of this group were designated A. Rubber was masticated for $5 \mathrm{~min}$, followed by the addition of $\mathrm{ZnO}$ and stearic acid and milled for $2 \mathrm{~min}$. Tetra methyl quinone was then added to the mix and milled for $1 \mathrm{~min}$. Carbon black at $10 \mathrm{phr}$ was added to the mix and milled for $2 \mathrm{~min}$. Such process is called CB_1. The remaining carbon black ( $c a$. $40 \mathrm{phr}$ ) was added to the mix along with oil and milled for 4 min. This was called CB_2 +oil. Subsequently, the addition of tert-butyl benzothiazole sulfenamide and sulfur required a milling time of 1 minute each. This sample was called A1. 20 phr of the total amount of $50 \mathrm{phr}$ carbon black was then added to the rubber; the remaining $30 \mathrm{phr}$ was added later to the rubber afterwards at the same time with the oil and is called A2. Using the same procedure, the samples with carbon black added to rubber at 30-20 and 40-10 phr was denoted A3 phr and $\mathrm{A} 4$, respectively.

Using the formula listed in Table-1, mixing was also carried out in accordance with the sequence and the time each

\begin{tabular}{ccc}
\multicolumn{3}{c}{ TABLE-1 } \\
& NATURAL RUBBER FORMULA \\
\hline No. & Materials & $\mathrm{Phr}$ \\
\hline 1 & RSS-1 & 100 \\
2 & ZnO & 5 \\
3 & Stearic acid & 2 \\
4 & Carbon Black N 330 & 50 \\
5 & Paraffinic oil & 5 \\
6 & Tetra methyl quinone & 2 \\
7 & tert-Butyl benzothiazole sulfenamide & 0.5 \\
8 & Sulfur & 2.5 \\
\hline
\end{tabular}

\begin{tabular}{ccc}
\multicolumn{3}{c}{ TABLE-2 } \\
SEQUENCE OF NATURAL RUBBER MIXING OF COMPOUND A \\
\hline No. & Materials & Time (min) \\
\hline 1 & RSS-1 & 5 \\
2 & ZnO & 2 \\
3 & Stearic acid & 2 \\
4 & Tetra methyl quinone & 1 \\
5 & CB_1 & 2 \\
6 & CB_2 +oil & 4 \\
7 & tert-Butyl benzothiazole sulfenamide & 1 \\
8 & Sulfur & 1 \\
\hline \multicolumn{2}{c}{} \\
\hline
\end{tabular}

sequence required, as shown in Table-3. The process of carbon black addition to the rubber was performed using the same method applied to the sequence in Table-2. The samples using the mixing sequence listed in Table- 3 were designated D. D1, D2, D3 and D4 were based on the mixing sequence of carbon black addition.

\begin{tabular}{ccc}
\multicolumn{3}{c}{ TABLE-3 } \\
SEQUENCE OF NATURAL RUBBER MIXING OF COMPOUND D \\
\hline No. & Materials & Time (min) \\
\hline 1 & RSS-1 & 3 \\
2 & CB_1 & 2 \\
3 & CB_2 + oil & 5 \\
4 & ZnO & 2 \\
5 & Stearic acid & 2 \\
6 & Tetra methyl quinone & 1 \\
7 & tert-Butyl benzothiazole sulfenamide & 1 \\
8 & Sulfur & 1 \\
\hline \multicolumn{3}{c}{}
\end{tabular}

Rubber was masticated for $3 \mathrm{~min}$. Carbon black was then added and the resulting mixture was milled for $7 \mathrm{~min}$. Carbon black (10 phr) was then added. This process was called CB_1 and required 2 min for milling. The remaining $40 \mathrm{phr}$ was added afterwards to the rubber with oil. This was called CB_2 + oil and required $5 \mathrm{~min}$ for milling. $\mathrm{ZnO}$ and stearic acid was added and milled for $2 \mathrm{~min}$, followed by the addition of tetra methyl quinone, sulfur and tert-butyl benzothiazole sulfenamide and milling for 1 min each.

The curing characteristics of the compound rubber were then determined using a rheometer MDR 2000. Based on the rheograph, the specimen was prepared and physical a characteristic test was performed. Some of the rubber compounds produced from the rubber mixing were tested on the bound rubber formation. One gram of rubber was dissolved in toluene for 4 days. The weight was measured before and after dissolution. After dissolution, the rubber sample was dried and 
weighed until it reached a constant weight. Bound rubber is the amount of rubber that does not dissolve in the toluene solvent ${ }^{10}$.

Detection method: The curing characteristics were determined using a rheometer MDR 2000 (ISO 6502-99) at $150{ }^{\circ} \mathrm{C}$. The physical properties test of vulcanized rubber was performed according to the ISO standard method listed in Table- 4 and the method employed to determine the amount of bound rubber of the rubber compounds was based on the equation reported by several authors ${ }^{3,4,11,12}$ as follows:

$$
\text { Bound rubber }=\frac{\mathrm{W}_{\mathrm{fg}}-\mathrm{W}\left(\frac{\mathrm{m}_{\mathrm{f}}}{\left(\mathrm{m}_{\mathrm{f}}+\mathrm{m}_{\mathrm{p}}\right)}\right)}{\mathrm{W}\left(\frac{\mathrm{m}_{\mathrm{p}}}{\left(\mathrm{m}_{\mathrm{f}}+\mathrm{m}_{\mathrm{p}}\right)}\right)} \times 100 \%
$$

where $\mathrm{W}_{\mathrm{fg}}$ is the weight of carbon black and gel, $\mathrm{m}_{\mathrm{f}}$ is the weight of the filler in the compound in $\mathrm{phr}, \mathrm{m}_{\mathrm{p}}$ is the weight of the polymer in the compound in phr and $\mathrm{W}$ is the weight of the specimen in the dry state.

\begin{tabular}{ccc} 
TABLE-4 \\
& $\begin{array}{c}\text { METHODS OF THE PHYSICAL PROPERTIES } \\
\text { TEST OF THE VULCANIZED RUBBER }\end{array}$ \\
\hline No. & Testing & Methods \\
\hline 1 & Hardness & ISO 7619(1)-2004 \\
2 & Tensile strength & ISO 37-2005 \\
3 & Modulus 500 \% & ISO 37-2005 \\
4 & Elongation at Break & ISO 37-2005 \\
5 & Tear resistance & ISO 34-2007 \\
6 & Abrasion resistance & ISO 4649-2002 \\
7 & Rebound resilience & ISO 4662-2009 \\
\hline
\end{tabular}

\section{RESULTS AND DISCUSSION}

Table-5 presents the curing characteristics of the rubber whose formula is listed in Table- 1 and mixed using the sequence shown in Table-2. Table-6 shows the curing characteristics using the mixing sequence listed in Table- 3 . The curing characteristics data in Tables 6 and 7 were processed beforehand to determine the cure rate of $\mathrm{A}$ and $\mathrm{D}$. The cure rate index (CRI) is a level of the cure rate. The cure rate of the vulcanization reaction increased with increasing cure rate index value. The cure rate index can be calculated using the following equation:

$$
\text { Cure rate index }(\mathrm{CRI})=\frac{100}{\mathrm{t}_{90}-\mathrm{t}_{\mathrm{s} 2}}
$$

TABLE-5

CURING CHARACTERISTICS OF COMPOUND A AT $150^{\circ} \mathrm{C}$

\begin{tabular}{lccccc}
\hline \multirow{2}{*}{ Characteristics } & \multirow{2}{*}{ Methods } & \multicolumn{4}{c}{ Compounds } \\
\cline { 3 - 6 } & & $\mathrm{A} 1$ & $\mathrm{~A} 2$ & $\mathrm{~A} 3$ & $\mathrm{~A} 4$ \\
\hline Maximum torque $(\mathrm{kg}-\mathrm{cm})$ & 16.65 & 16.14 & 15.91 & 13.93 \\
Minimum torque $(\mathrm{kg}-\mathrm{cm})$ & $\mathrm{ISO}$ & 1.64 & 1.68 & 1.50 & 1.25 \\
Max torque-min torque $(\mathrm{kg}-\mathrm{cm})$ & $6502-99$ & 15.01 & 14.46 & 14.41 & 12.68 \\
Curing optimum $\left(\mathrm{t}_{90}\right)(\mathrm{min})$ & & 11.57 & 11.02 & 11.05 & 11.16 \\
Scorch time $\left(\mathrm{t}_{\mathrm{s} 2}\right)(\mathrm{min})$ & 2.19 & 2.25 & 2.29 & 2.33 \\
\hline
\end{tabular}

Fig. 1 for A and Fig. 2 for D show the cure rate index correlation of $\mathrm{A}$ and $\mathrm{D}$ with the rubber mixing process.
TABLE-6

CURING CHARACTERISTICS OF COMPOUND D AT $150^{\circ} \mathrm{C}$

\begin{tabular}{lccccc}
\hline \multirow{2}{*}{ Characteristics } & \multirow{2}{*}{ Methods } & \multicolumn{5}{c}{ Compounds } \\
\cline { 3 - 6 } & & $\mathrm{D} 1$ & $\mathrm{D} 2$ & $\mathrm{D} 3$ & $\mathrm{D} 4$ \\
\hline Maximum torque $(\mathrm{kg}-\mathrm{cm})$ & & 15.51 & 16.85 & 14.63 & 15.99 \\
Minimum torque $(\mathrm{kg}-\mathrm{cm})$ & $\mathrm{ISO}$ & 1.55 & 1.76 & 1.47 & 1.68 \\
Max torque-min torque $(\mathrm{kg}-\mathrm{cm})$ & $6502-99$ & 13.96 & 15.09 & 14.16 & 14.31 \\
Curing optimum $\left(\mathrm{t}_{90}\right)(\mathrm{min})$ & & 10.23 & 11.09 & 10.24 & 10.39 \\
Scorch time $\left(\mathrm{t}_{\mathrm{s} 2}\right)(\mathrm{min})$ & & 2.18 & 2.15 & 2.18 & 2.27 \\
\hline
\end{tabular}

TABLE-7

PHYSICAL PROPERTIES OF RUBBER A

\begin{tabular}{llccccc}
\hline \multirow{2}{*}{ No } & \multirow{2}{*}{ Testing } & \multirow{2}{*}{ Methods } & \multicolumn{5}{c}{ Vulcanization } \\
\cline { 3 - 7 } & & A1 & A2 & A3 & A4 \\
\hline 1 & Hardness, Shore A & $7619(1)-$ & 66 & 67 & 64 & 63 \\
& & 04 & & & & \\
2 & Tensile strength $\left(\mathrm{kg} / \mathrm{cm}^{2}\right)$ & $37-05$ & 251 & 243 & 245 & 255 \\
3 & Modulus 500 \% $\left(\mathrm{kg} / \mathrm{cm}^{2}\right)$ & $37-05$ & 202 & 212 & 213 & 211 \\
4 & Elongation at break (\%) & $37-05$ & 580 & 550 & 550 & 580 \\
5 & Tear resistance $\left(\mathrm{kg} / \mathrm{cm}^{2}\right)$ & $34-07$ & 160 & 155 & 120 & 144 \\
7 & Abrasion resistance & $4649-02$ & 112.5 & 131.1 & 112.3 & 112.4 \\
& (DIN mm $\left.^{3}\right)$ & & & & & \\
8 & Rebound resilience (\%) & $4662-09$ & 50 & 54 & 52 & 52 \\
\hline
\end{tabular}

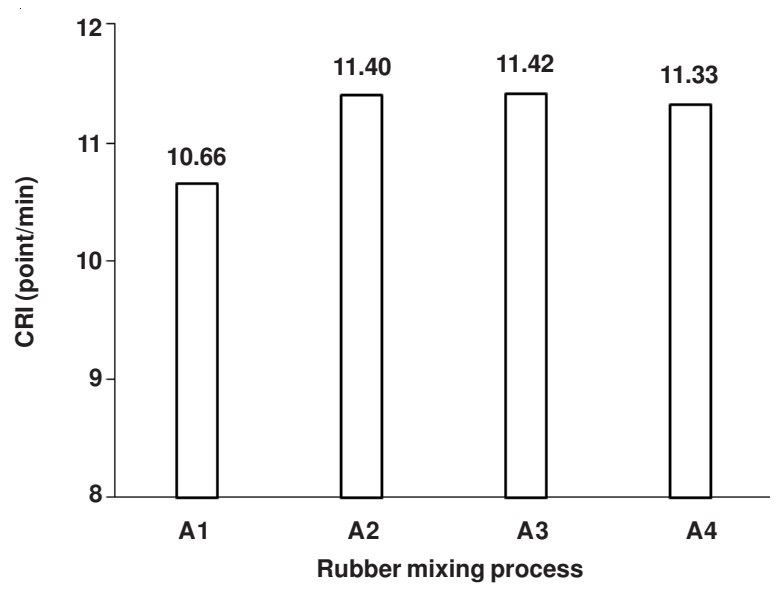

Fig. 1. Cure rate index of A under the rubber mixing process effect

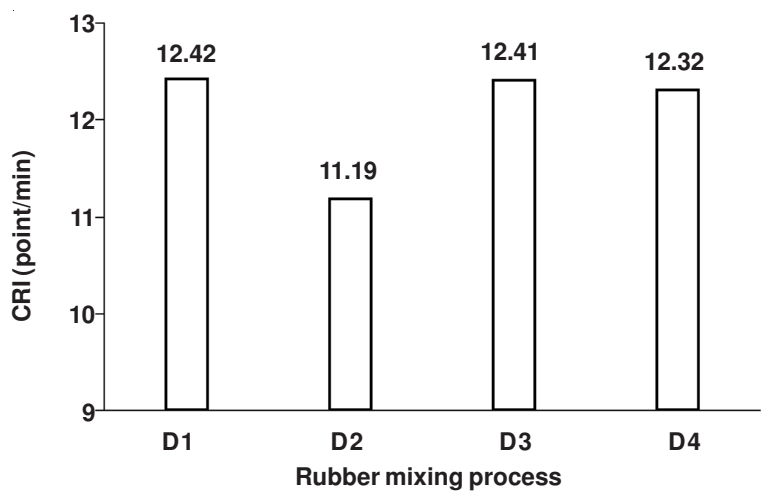

Fig. 2. Crude rate index of $\mathrm{D}$ under the rubber mixing process effect

The rubber mixing process affects the cure rate index of A and D significantly (Figs. 1 and 2). The cure rate index of A showed a significance change (Fig. 1), increasing from A1 to A4, where Fig. 2 shows that the cure rate index of D shows a significant change, increasing from D1 to D4. The cure rate index of $\mathrm{A}$ in Fig. 1 is lower than that of $\mathrm{D}$ in Fig. 2. This 
means that the vulcanization reaction of $\mathrm{D}$ is faster than that of $\mathrm{A}$. To determine the rate of the vulcanization reaction from A1 to A4 and from D1 to D4, the changes in their torque values were measured. A high torque value indicates that the crosslink density is high. A high crosslink density does not ensure that the vulcanization rate is high. Bound rubber is still needed to support the vulcanization rate. Therefore, the torque value of A was higher than that of $\mathrm{D}$ but the vulcanization rate of $\mathrm{A}$ was lower than that of $\mathrm{D}$. This was attributed to the higher amount of bound rubber of $\mathrm{D}$ than $\mathrm{A}$. The torque decreased both from A1 to A4 and from D1 to D4. This means that the crosslink density decreases. The special case from A1 to A4, a decrease in crosslink density, was followed by a decrease in bound rubber. Accordingly, there was an increase in some of the physical properties but there are any decreases of that. In contrast, the crosslink density and bound rubber increased from D1 to D4. The torque from D1 to D4 decreased but the physical properties increased.

The mastication time and sequence of the rubber mixing process were correlated with the physical properties of the rubber vulcanizates of $\mathrm{A}$ and $\mathrm{D}$ and are listed in Tables 7 and 8 , respectively. Both the physical properties of the vulcanizate tests on A and D were performed according to the ISO standard method.

TABLE-8

\section{PHYSICAL PROPERTIES OF RUBBER D}

\begin{tabular}{llccccc}
\hline \multirow{2}{*}{ No } & \multirow{2}{*}{ Testing } & Methods & \multicolumn{4}{c}{ Vulcanization } \\
\cline { 3 - 7 } & & & D1 & D2 & D3 & D4 \\
\hline 1 & Hardness, Shore A & $7619(1)-$ & 61 & 67 & 68 & 68 \\
& & 04 & & & & \\
2 & Tensile strength $\left(\mathrm{kg} / \mathrm{cm}^{2}\right)$ & $37-05$ & 270 & 259 & 267 & 271 \\
3 & Modulus 500 \% $\left(\mathrm{kg} / \mathrm{cm}^{2}\right)$ & $37-05$ & 248 & 249 & 256 & 253 \\
4 & Elongation at break $(\%)$ & $37-05$ & 520 & 520 & 520 & 530 \\
5 & Tear resistance $\left(\mathrm{kg} / \mathrm{cm}^{2}\right)$ & $34-07$ & 142 & 152 & 166 & 182 \\
7 & Abrasion resistance & $4649-02$ & 132.4 & 114.9 & 113.4 & 112.8 \\
& $\left(\right.$ DIN mm $\left.{ }^{3}\right)$ & & & & & \\
8 & Rebound resilience $(\%)$ & $4662-09$ & 60 & 55 & 53 & 55 \\
\hline
\end{tabular}

Table-7 shows that the tensile strength, modulus $500 \%$ and elongation at break show a significant increase, whereas the tear resistance, hardness and rebound resilience did not show any significant change. In this case, the rubber mixing process plays an important role in establishing the aforementioned changes. The initial process of adding a larger amount of carbon black with the concomitant addition of a second amount of carbon black with the addition of a small amount of oil can cause the carbon black aggregates to spoil and disperse better in the rubber. As a result, the rubber viscosity decreases, leading to a decrease in hardness and tear resistance. Better-dispersed carbon black causes the surface to adsorb rubber molecules, initiating a better function of carbon black as the reinforcing filler. Subsequently, the tensile strength, modulus $500 \%$ and elongation at break increased and the rebound resilience decreased.

Table- 8 suggests that the hardness, tensile strength, modulus $500 \%$, elongation at break, tear resistance and abrasion resistance show a profound increase, whereas the rebound resilience showed a decrease. The reasons are addition of larger amount of carbon black at the initial process, the short mastication time and the different sequence of the rubber mixing process. In this case, however, the effects of the sequence of the rubber mixing process are quite substantial because there are differences in the mastication time and the sequence of the process of addition of carbon black to the rubber. In cases $\mathrm{A}$ and $\mathrm{D}$, the mastication time was 5 and 3 min, respectively. The same was observed in the process of carbon black addition into the rubber. In case A, carbon black was added some time after adding rubber chemicals. On the other hand, in case $\mathrm{D}$, the process of addition of carbon black into the rubber was performed before adding the rubber chemicals. In case D, carbon black was dispersed better than that of A because carbon black was mixed with rubber before adding the rubber chemicals. This can cause the higher adsorption of rubber molecules on the surface of carbon black due to the high shearing force of rubber compared to A. Therefore, the physical properties of D became better than that of A.

Figs. 3 and 4 for A and D, respectively, show the correlation between the mastication time and the sequence of the rubber mixing process with bound rubber.

Fig. 3 shows that the bound rubber is affected by the rubber mixing process. The amount of bound rubber decreases significantly from A1 to A4. The tear resistance decreased from A1 to A4 (Table-7). In the rubber mixing process of A, the addition of a larger amount of carbon black at the initial stages of the process and the simultaneous addition of the remaining carbon black with oil does not ensure that carbon black will be well dispersed. This was caused by the 5 min of mastication time and the addition of carbon black after some of the rubber chemicals had been added to the rubber. The carbon black surface was tainted with the quantity of rubber chemicals, making it difficult to adsorb the rubber molecules.

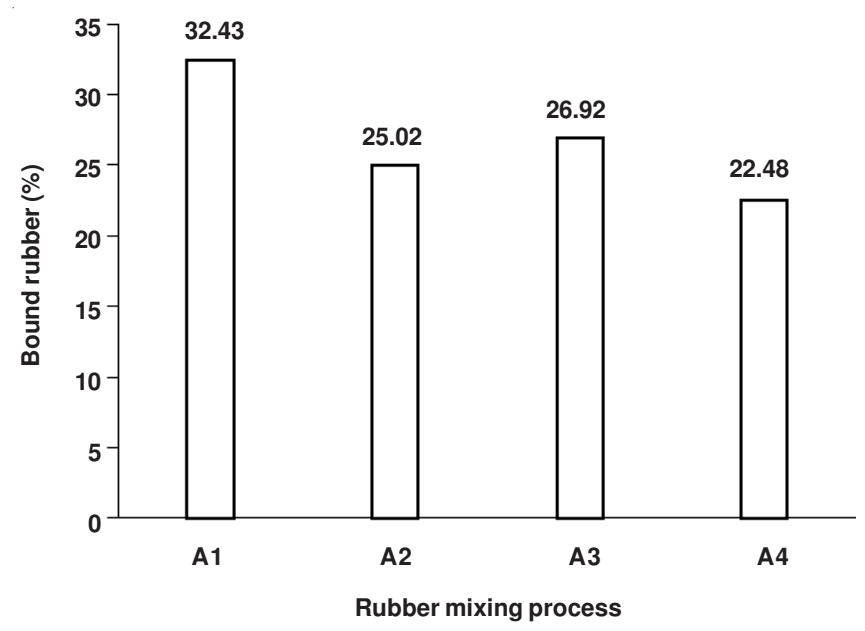

Fig. 3. Bound rubber of A under the rubber mixing process effect

Fig. 4 shows that the bound rubber increased significantly from D1 to D4. In this case, the process of adding a larger amount of carbon black at the initial stages of the mixing process and adding the remaining carbon black simultaneously with oil caused an increase in bound rubber.

Furthermore, the shortage of 3 min mastication time and the addition of carbon black before adding the rubber chemicals results in an increase in rubber viscosity and an 


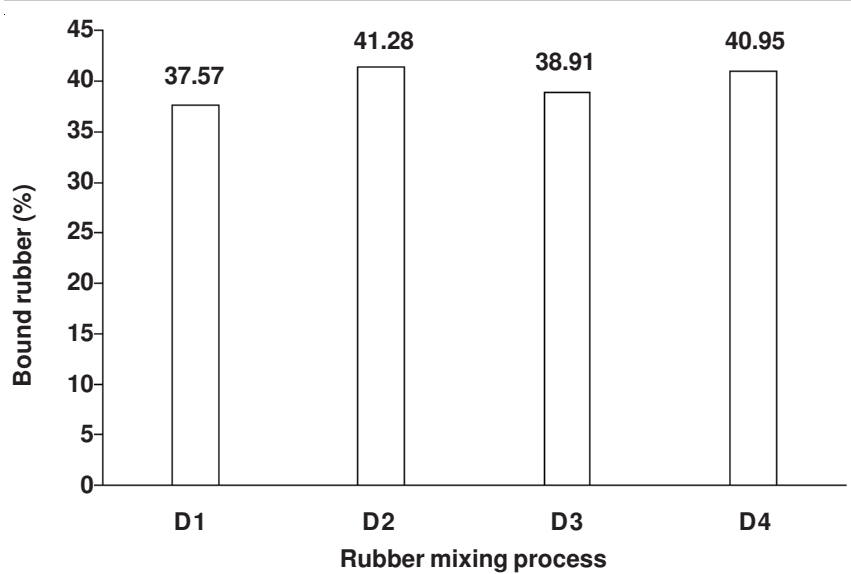

Fig. 4. Bound rubber of $\mathrm{D}$ under the rubber mixing process effect

untainted carbon black surface. This results in a better carbon black dispersion caused by the high shearing force of rubber during the mixing process and the carbon black surface can adsorb the rubber molecules easily. The increase in bound rubber is indicated by the changes in the physical properties listed in Table-8. Figs. 3 and 4 show that bound rubber of D is larger than that of $\mathrm{A}$, meaning that the change in the physical properties of D occur more significantly that of A. Wang ${ }^{6,7}$ reported that the formation of bound rubber varied significantly, along with the changes in the mixing sequence of the rubber chemicals. The rubber milled with the existence of rubber chemicals can decrease the bound rubber content, compared to the rubber milled without rubber chemicals. The substances of a part of the surface and active center of the existing carbon black that can be used to adsorb rubber molecules can be reduced by the adsorption of a number of rubber chemicals molecules. If the rubber molecules are adsorbed successfully on the surface of carbon black, it will be very difficult to replace it by the adsorption of rubber molecules. Therefore, the amount of bound rubber decreases.

\section{Conclusion}

The rubber mixing process affected the formation of bound rubber and the physical properties of vulcanized natural rubber. These changes are affected by the mastication time and the sequence of carbon black addition to the rubber. The rubber viscosity decreases with increasing mastication time. A low rubber viscosity causes less of the carbon black aggregates to break during the mixing process. Therefore, a large amount of carbon black dispersed into the rubber is still in the form of large aggregates. In this case, the carbon black surface is small, hence a small amount of rubber molecules are adsorbed. Increasing the amount of carbon black added in the initial stages of the mixing process will improve its effect on bound rubber formation and physical properties. The initial addition of carbon black to the rubber in the initial stages of the mixing process, followed by the addition of rubber chemicals, results in better bound rubber and physical properties than with the simultaneous addition of carbon black with the rubber chemicals. With the initial addition of carbon black, the surface of the available carbon black adsorbs the rubber molecules more effectively than when carbon black and rubber chemicals are added simultaneously. In this case, most of the surface of the existing carbon black has already been stained by rubber chemicals. Therefore, only a small amount of rubber molecules are adsorbed on the carbon black surface. In case of the initial addition of carbon black followed by rubber chemicals, the act of adding more carbon black in the initial stages of the rubber mixing process can increase the amount of bound rubber and the physical properties. In contrast, in case of the simultaneous addition of carbon black and rubber chemicals, the amount of bound rubber decreases and some of the physical properties increase.

\section{ACKNOWLEDGEMENTS}

The authors acknowledged the support of the Directorate General of Higher Education Republic of Indonesia (in the scheme of Doctor Dissertation Grant 2010), Polymer Technology Laboratory of Chemical Engineering Department Faculty of Engineering Gadjah Mada University and Bogor Research Station for Rubber Technology.

\section{REFERENCES}

1. Indian Rubber Institute, Rubber Engineering, Indian Rubber Institute, McGraw-Hill, Professional Engineering, New York, Ch. 6 (2000).

2. M. Morton, Rubber Technology, Van Nostrand Reinhold, New York, edn. 3, Ch. 2 (1987).

3. S.S. Choi, K.J. Hwang and B.T. Kim, J. Appl. Polym. Sci., 98, 2282 (2005).

4. S.S. Choi, J. Appl. Polym. Sci., 93, 1001 (2004).

5. M.J. Wang, In Proceedings of International Rubber Conference (IRC), Lyon, France (2006).

6. M.J. Wang, Rubber Chem. Technol., 71, 520 (1998).

7. M.J. Wang, Paper Presented at a Meeting of the Rubber Division, American Chemical Society, Indianapolis, Indiana, US (1998).

8. M. Gerspacher, In Proceedings of South Brazilian Rubber Conference, Bento Goncalves, RS (2003).

9. F.M. Dannenberg, Rubber Chem. Technol., 59, 512 (1986).

10. G. Kraus, Reinforcement of Elastomers, John Wiley \& Sons, New York Ch. 4 (1965).

11. S. Qian, J. Huang, W. Guo and C. Wu, J. Macromol. Sci. B: Phys., 46, 453 (2007).

12. T. Wang, M.J. Wang, J. Shell and N. Tokita, Kautsch Gummi Kunstst, 53, 497 (2000). 